\title{
FEMINISMO E TEORIA CRÍTICA: CRUZAMENTOS ENTRE QUESTÕES DE GÊNERO E MARXISMO
}

\author{
Laiz Fraga Dantas ${ }^{1}$
}

RESUMO: Esse trabalho pretende tratar da relação entre o marxismo da teoria crítica e questões de gênero através do paralelo entre o texto de Marcuse, Marxismo e Feminismo, e o modelo para a teoria crítica contemporânea de Nancy Fraser. A partir da compreensão da forma como a teoria crítica tratou os elementos do marxismo na sua filosofia da primeira geração (Marcuse) e na sua versão contemporânea (Fraser), traçaremos as consequências das mudanças na assimilação do marxismo entre esses dois modelos de teoria crítica e a forma como se compreendeu a questão de gênero.

PALAVRAS-CHAVE: Teoria Crítica, Marxismo, Gênero

ABSTRACT: This paper aims to address the relationship between the marxism of the critical theory and gender issues through the parallel between the text Marxism and Feminism of Marcuse and the critical theory of Nancy Fraser. From the understanding of how critical theory treats 
FEMINISMO E TEORIA CRÍTICA: CRUZAMENTOS ENTRE QUESTÕES DE GÊNERO...

the marxists elements in the philosophy of its first generation (Marcuse) and in its contemporary version (Fraser), we will expose the consequences of the changes in the assimilations between these two critical theory models and how these theories understand the problem of gender.

KEYWORDS: Critical Theory, Marxism, Gender 
Horkheimer, em seu ensaio Teoria tradicional e Teoria Crítica (1991), apresentou a teoria crítica como um desdobramento da filosofia de Marx e da intenção prática de superar a filosofia tradicional - e sua incessante atividade de produzir descrições do mundo -, em direção a um conhecimento que possa finalmente modificar a realidade. A teoria crítica se define através da necessidade de produzir teoria social atenta ao seu tempo, capaz de fornecer um diagnóstico de sua época, expondo suas contradições e tensões e, em conjunto, um prognóstico que aponte os potenciais de emancipação possíveis. Assim, a emancipação é um elemento central para a teoria crítica que - tanto em sentido teórico como prático - pretende produzir discursos que compreendam o que constitui a emancipação e sob quais condições ela é possível.

Esses elementos apontados por Horkheimer são centrais para a teoria crítica até hoje que, apesar de ter realizado mudanças significativas em seu programa, mantém o interesse prático-emancipatório vivo. Apesar disso, as questões de gênero, com clara relevância para as relações sociais, só muito recentemente ganharam evidência na teoria crítica. Na crítica ao Esclarecimento, oferecida por Adorno e Horkheimer na Dialética do Esclarecimento (2006), os autores apontam o caráter patriarcal da razão ${ }^{2}$, 
FEMINISMO E TEORIA CRÍTICA: CRUZAMENTOS ENTRE QUESTÕES DE GÊNERO...

mas, da chamada primeira geração da teoria crítica, Marcuse é quem vai dedicar atenção especial para a análise dos movimentos feministas de sua época e realizar um exame sobre os desdobramentos de suas reivindicações para o projeto de crítica ao capitalismo da Escola de Frankfurt. Somente com a posterior virada iniciada por Habermas com sua Teoria do Agir Comunicativo, sua reconstrução do marxismo e aproximação com a filosofia da linguagem e um tipo de pragmatismo -, se colocou no centro do debate da teoria crítica as questões de reconhecimento e, com isso, se abriu espaço para as questões de gênero. Autoras contemporâneas dessa corrente assinalam a necessidade de se construir uma teoria crítica feminista e põem em debate os pressupostos dessa teoria, adequando-os à pretensão de se construir uma teoria social atenta à dominação de gênero. Nesse texto farei um paralelo entre a relação do marxismo da teoria crítica e a questão de gênero, considerando como essa tradição utilizou as ferramentas oferecidas pela filosofia de Marx e como tratou do tema do gênero em dois momentos distintos da elaboração da teoria crítica. Tratarei do feminismo marxista defendido por Marcuse, autor da primeira geração da teoria crítica, em paralelo com a filosofia de Nancy Fraser, autora contemporânea que produz uma teoria crítica feminista.

Marcuse, em seu texto Marxism and Feminism (2005), inicia afirmando que o movimento feminista é, para ele, o 
mais importante e mais radical movimento político de sua época e estudá-lo parece relevante devido ao caráter transversal que assume as suas reivindicações. $\mathrm{O}$ movimento feminista colocaria em questão tanto as relações sociais, os costumes e os papeis sociais, como também o capitalismo e sua dinâmica. É justamente a capacidade de problematizar esses dois níveis que torna o feminismo tão radical. Criticando alguns tipos de marxismos, Marcuse defende que uma mudança na estrutura econômica de uma sociedade não garantiria uma mudança qualitativa nas suas relações interpessoais. Para ele, o capitalismo, ao reduzir as relações a relações econômicas, produziu uma série de alienações que negariam a própria condição humana, impedindo a realização de suas potencialidades, abstraídas nessa sociedade. Marcuse vai apontar que os mecanismos que proporcionam a dominação, resultante da estrutura capitalista econômica e política, também invadem a esfera das relações interpessoais e produzem distorções para além da dominação de classe, como a opressão da mulher. Assim, o autor assinala a insuficiência de uma solução meramente econômica e propõe uma "revolução total". Nesse sentido, as questões de gênero tornam-se peça importante em sua proposta pois, para o autor, o movimento feminista propõe uma mudança qualitativa nas relações sociais, que vão além de uma mudança institucional ou na estrutura econômica. 
FEMINISMO E TEORIA CRÍTICA: CRUZAMENTOS ENTRE QUESTÕES DE GÊNERO...

Para Marcuse, os valores que conduzem o capitalismo são os valores do masculino, a saber, assertividade, produtividade, eficiência, competitividade, força, virilidade e racionalidade (sempre definida em contraponto à sensibilidade). Essa é a "ética do trabalho" do capitalismo que permeia tanto as relações de produção como as relações interpessoais, produzindo distorções no sistema social como um todo. Para Marcuse, os valores hegemônicos da sociedade capitalista são opostos ao que considera os "valores do feminino". Acompanhando Simone de Beauvoir, Marcuse afirma que na sociedade patriarcal as mulheres foram submetidas a um tipo de repressão que fez com que seu desenvolvimento mental e psicológico assimilasse características específicas, constituindo o que socialmente se chama de "o feminino". Marcuse afirma que essa "natureza" feminina não é em nenhum sentido natural ou biológica, mas sim condicionada socialmente e tornada uma natureza secundária.

Os valores do feminino seriam a cooperação, o cuidado, a sensibilidade e a não-violência. Esses valores Marcuse identifica com o Eros, o oposto aos valores masculinos que sustentam a civilização capitalista patriarcal. Em consonância com sua proposta em Eros $e$ Civilização (1975), Marcuse aponta a necessidade de promover os valores do feminino na sociedade para que se possa recuperar o Eros deformado pela exploração e 
dominação. Possibilitar uma "feminização" da razão masculinizada e da civilização significaria proporcionar a aproximação do Eros com a razão. Marcuse vai defender um feminismo socialista que vai além de uma crítica às relações econômicas e à subjugação de classe e propõe uma mudança radical no princípio de realidade do capitalismo e nas relações patriarcais.

Essa tentativa de Marcuse de aliar o vocabulário marxista com a questão de gênero pode nos dar pistas para revelar os limites desse vocabulário para tratar de questões que envolvem reconhecimento ${ }^{3}$. No texto $O$ Feminismo, $o$ capitalismo e a astúcia da história (2009), Nancy Fraser defende que a crítica ao caráter economicista do marxismo e a ênfase no debate cultural defendida por Marcuse - pela nova esquerda e pela então nascente segunda onda do feminismo - proporcionou um ganho crucial, ao abrir espaço na crítica marxista da sociedade para esta e outras questões de identidade. Essa mudança de perspectiva acerca do marxismo veio acompanhada de uma transformação da própria organização do capitalismo. O capitalismo de Estado tornou-se neoliberal, baseado no bem-estar social, na diminuição do Estado e na ênfase à garantia das liberdades individuais. Esse tipo de capitalismo menos agressivo, com a figura do Estado reduzida, e que garantia uma série de benefícios aos trabalhadores, não oferecia uma resistência direta às lutas de identidade, ao contrário, por 
FEMINISMO E TEORIA CRÍTICA: CRUZAMENTOS ENTRE QUESTÕES DE GÊNERO...

vezes assume essas pautas sem que isso significasse um empecilho à dinâmica do capitalismo. Fraser aponta que, nesse cenário em que o capitalismo e o aparato do Estado não se apresentavam como uma resistência direta, as lutas por identidade abandonaram a crítica social ampla e sobre a organização econômica e focaram-se na luta por expressão das identidades marginalizadas ${ }^{4}$. Esse abandono do marxismo pode ser interpretado como consequência da falta de ferramentas da teoria marxista para tratar as questões de gênero e questões de identidade em geral - se descoladas da estrutura econômica como fator principal da análise. $\mathrm{O}$ que se questiona então é: haveria no vocabulário marxista ferramentas para dar conta das questões de reconhecimento? É preciso lidar com essa questão para oferecer uma alternativa ao abandono do vocabulário marxista.

A saída para Fraser não é um retorno ao marxismo da nova esquerda, como também não é adotar a ênfase das correntes contemporâneas no reconhecimento. Fraser aponta uma terceira alternativa. No seu texto Um futuro para o marxismo (1999), Fraser problematiza o lugar do marxismo na nossa atual condição "pós-socialista", em que ele deixa de ser o discurso mestre de oposição política em sociedades capitalistas. Para Fraser, para que o marxismo possa manter a conexão estreita entre teoria e prática e promova, como queria o próprio Marx, o auto- 
esclarecimento das lutas e aspirações de uma época, é preciso reposicionar elementos basilares dessa teoria. Para ela, isso significa aproximar-se das teorias do discurso pósestruturalistas, das teorias feministas e sobre raça. Assim torna-se possível problematizar noções centrais dessa teoria, sobretudo, aponta a autora, redefinir a noção de identidade coletiva para que esta possa dar espaço para a noção de gênero e de raça, sem retomar uma hierarquia que privilegia a economia.

Para Fraser, existem duas definições possíveis para a categoria "classe". A primeira é a ideia de classe "em si" que a autora define como "uma categoria teórica objetiva que pode ser atribuída aos atores sociais por um observador independentemente da autodescrição e autoconsciência do observado" (FRASER, 1999. P.5), ou seja, classe como uma categoria objetiva definida por um observador "científico". A segunda forma tem sido denominada "classe para si". Como a própria locução hegeliana já sugere, supõe a "autoconsciência dos atores sociais, sua identidade social coletiva e participação em um grupo social mobilizado" (FRASER, 1999. P.5). A classe aqui é definida como uma identidade coletiva mobilizada. O marxismo procura conjugar as duas definições, compreendendo o sujeito revolucionário como aquele que objetivamente ocupa a posição de proletariado e que se entende como classe. Porém, no atual cenário a separação entre os dois conceitos 
FEMINISMO E TEORIA CRÍTICA: CRUZAMENTOS ENTRE QUESTÕES DE GÊNERO...

é clara. Primeiro, é mais difícil hoje localizar claramente quais sujeitos ocupam a posição de classe operária e, segundo, esses indivíduos não apresentaram historicamente uma consciência de classe coesa e revolucionária. A classe em si não se tornou classe para si - esse foi um problema crucial para a primeira geração da teoria crítica de Adorno, Horkheimer e Marcuse em sua apropriação do marxismo.

A suposição marxista tem por consequência a ideia de que as identidades sociais coletivas são de algum modo subscritas pelas posições estruturais dos atores sociais. Com um vocabulário desse tipo torna-se complicado tratar de questões de identidade. Para a autora, é preciso assumir que as identidades sociais são culturalmente construídas através de processos culturais relativamente autônomos e contingentes que escapam das determinações estruturais. Desse modo, onde o marxismo propõe convergência entre posições estruturais e grupos mobilizados, Fraser vai assumir a autonomia das identidades em relação às determinações estruturais e a relativa contingência dos processos pelos quais as filiações se formam e os grupos são mobilizados. Isso tem um impacto importante para a teoria social. Como a ideia de identidade coletiva é um resultado construído de processos culturais contingentes relativamente autônomos da estrutura social, marcadores como gênero, raça e classe são inteiramente equivalentes, sendo redutor formular uma teoria social crítica que 
dispense qualquer um desses elementos na definição de identidades coletivas.

Essas críticas fundamentam a redefinição de Fraser de alguns elementos do marxismo e do feminismo da nova esquerda. Fraser deixa de lado a perspectiva totalizadora acerca da sociedade capitalista como um sistema monolítico de estruturas de opressão entrelaçadas que se reforçam entre si. É esse ponto de vista que parece supor a hipótese para o feminismo, sustentada por Marcuse. Para ele, a opressão sofrida pelas mulheres, bem como a exploração e mal-estar proporcionado pela sociedade capitalista, tem uma razão estrutural expressa no princípio de realidade do capitalismo. Assim, essa distorção é intrínseca à forma de organização da sociedade capitalista e aparece tanto na estrutura econômica como nas relações interpessoais. A revolução é uma revolução total quando subverte esse elemento, tornando possível uma sociedade baseada no seu oposto, o Eros. Desse modo, Marcuse mantém viva a intenção revolucionária do marxismo, que parece ter sido esquecida pelas correntes mais contemporâneas. $\mathrm{O}$ autor pensa a mudança social de maneira radical, considerando a superação do modo de produção capitalista e do modo de vida a ele atrelado. Fraser, por exemplo, sobre a questão material, fala em redistribuição, que significaria promover uma forma mais igualitária de distribuir a riqueza no capitalismo. Porém, a autora não parece ter como horizonte 
FEMINISMO E TEORIA CRÍTICA: CRUZAMENTOS ENTRE QUESTÕES DE GÊNERO...

uma perspectiva revolucionária de superar o modo de produção do capitalismo, como Marx. Como escreve Silva, em relação ao conceito de redistribuição de Fraser, na sua filosofia "não se discute e problematiza sobre produção e a forma que esta assume na sociedade capitalista. O argumento parece pressupor que a luta redistributiva deve se preocupar com a forma de divisão da riqueza e da renda, e não com a forma de produção dessa mesma riqueza" (SILVA, 2010. P148).

Fraser vai assumir que a sociedade capitalista tardia é profundamente diferenciada e, como escreve a autora, "produz fraturas entre o sistema econômico e o sistema de parentesco, entre a família e a vida pessoal, entre o sistema de status e a hierarquia de classe" (FRASER, 1997. P.129). Por isso, é redutor conceber a desvalorização do feminino como simplesmente parte do modelo de regulação social do capitalismo e, portanto, não bastaria tornar o feminino dominante na sociedade capitalista para modificar a estrutura das relações sociais e do próprio capitalismo. Não é possível conjugar as questões de identidade e os problemas da estrutura econômica e política do capitalismo tratando a questão de gênero através do mesmo vocabulário que se trata a questão econômica. Com intensão de unificar as reivindicações culturais e econômicas se acaba considerando um princípio único para explicar ambas as formas de injustiças, localizando esse fator na própria 
estrutura do capitalismo. Para expor as consequências de reduções desse tipo, Fraser vai analisar grupos que ela denomina de coletividades bivalentes, que sofrem simultaneamente exploração de classe e têm sua identidade desvalorizada. Esses grupos são, para ela, aqueles que sofrem opressões de gênero e "raça". Em relação a esses grupos, oferecer uma solução que somente considere o viés da opressão político-econômica ou cultural separadamente é ineficaz para combater esse tipo de opressão de maneira efetiva. Fraser vai assumir que redistribuição e reconhecimento, mesmo que estejam, na prática, muitas vezes articulados, são conceitos analiticamente distintos e que, por isso, precisam ser considerados por vieses teóricos distintos.

O debate entre Marcuse e Fraser expõe o processo de mudança na teoria crítica da primeira geração até o cenário atual. Esse processo evidencia a forma como a teoria modificou sua apropriação do marxismo reconstruindo (e em alguns casos abandonando) elementos dessa teoria. Fraser, por um lado, critica a abordagem marxista economicista que, mesmo quando consegue inserir a questão de gênero como um problema relacionado ao capitalismo, o faz tornando o problema um elemento da dinâmica do capitalismo. Por outro lado, atualiza na teoria crítica a separação basilar do marxismo entre cultura e economia, defendendo essa distinção considerada obsoleta 
FEMINISMO E TEORIA CRÍTICA: CRUZAMENTOS ENTRE QUESTÕES DE GÊNERO...

por alguns autores da própria teoria crítica contemporânea que, como parte da reconstrução do marxismo, abandonaram a atenção à questão material em favor das questões de reconhecimento. $O$ que parece crucial para Fraser é perceber que através de abordagens que apontam o cerne das injustiças no modelo econômico, ou aqueles que reduzem a crítica social ao problema do reconhecimento, se cria uma falsa oposição entre conceitos - redistribuição e reconhecimento - que na verdade são complementares e cuja conjugação não só lhe parece plenamente possível como também extremamente necessária para uma teoria da justiça apta a lidar com os problemas de nosso tempo.

\section{NOTAS}

${ }^{1}$ Doutoranda em Filosofia pela Universidade Federal da Bahia (UFBA). E-mail: laizfragadantas@gmail.com.

2 Por exemplo, na análise sobre A Odisseia da Dialética do Esclarecimento, na exposição sobre o episódio de Circe, Adorno e Horkheimer expõem o caráter patriarcal da razão como um dos mecanismo de dominação do esclarecimento. Como escrevem os autores, Circe é uma figura mitológica que atrai os viajantes para a sua ilha, os seduz e, em seguida, os transforma em animais. A forma animal simboliza a submissão do homem à pulsão instintiva e "remete à fase mágica propriamente dita” (ADORNO, HORRKHEIMER 2006. P. 65). 
Assim, Circe representaria o instinto, o outro da razão, no qual o corpo, a matéria e a fantasia tem supremacia. A astúcia de Ulisses em não ceder aos encantos da hetaira representaria o triunfo da razão sobre os instintos e a sua repressão. Ulisses vence os encantos de Circe propondo a ela um contrato. Esse contrato representaria o casamento burguês, que garante a autoconservação masculina, a dominação da mulher, dos instintos e a reprodução da sociedade burguesa. "o casamento é a via média que a sociedade segue para acomodar a isso: a mulher continua a ser impotente na medida que o poder só lhe é concedido pela mediação do homem" (ADORNO, HORRKHEIMER 2006. P. 65). Adorno e Horkheimer apontam que a forma como a razão se estrutura é marcada pela sua dominação sobre seu outro. Nesse sentido, a razão se opõe às pulsões e à fantasia - identificados com o feminino -, elementos aos quais se deve resistir pra que a razão possa operar. As raízes patriarcais do discurso filosófico, e a racionalidade que o sustenta, são apenas apontadas e não exploradas profundamente pelos autores.

${ }^{3}$ Por reconhecimento se compreende a forma de definir a injustiça como "cultural ou simbólica. Aqui a injustiça se radica nos padrões sociais de representação, interpretação e comunicação. Seus exemplos incluem a dominação cultural, o ocultamento e o desrespeito" (FRASER, 2006. P. 232)

${ }^{4}$ Fraser, no seu texto O feminismo, o capitalismo e a astúcia da história, afirma que, contraditoriamente, foi a crítica da nova esquerda que proporcionou uma cisão entre os movimentos de identidade e de redistribuição que - no cenário atual - assumiram linguagens distintas e alimentaram uma oposição aparentemente inconciliável. Fraser vê uma afinidade perversa entre o neoliberalismo e as consequências de um feminismo direcionado somente ao debate sobre identidade, desligado do debate marxista sobre redistribuição. Para a autora, esse feminismo legitima uma política neoliberal na medida em que não oferece oposição a esta política, ao contrário, endossa a ênfase nas liberdades individuais. 
FEMINISMO E TEORIA CRÍTICA: CRUZAMENTOS ENTRE QUESTÕES DE GÊNERO...

Por isso para Fraser é crucial se reapropriar da crítica social e da estrutura econômica.

\section{REFERÊNCIAS BIBLIOGRÁFICAS}

ADORNO, T. HORKHEIMER, M. Dialética do Esclarecimento - Fragmentos filosóficos. Editora Zahar, Rio de Janeiro, 2006.

FRASER, N. Da redistribuição ao reconhecimento? Dilemas da justiça numa era "pós-socialista". T RAD. Julio Assis Simões. In: Cadernos de Campo, n ${ }^{\circ}$ 14/15, p.231-239, 2006.

FRASER, N. Heterosexism, misrecognition and capitalism: a response to Judith Butler In: Social Text 52-53, p. 279-289, 1997.

FRASER, N. Mapeando a imaginação feminista: da redistribuição ao reconhecimento e à representação. Trad. Ramayana Lira. Revista Estudos Feministas, 2007.

FRASER, N. O Feminismo, o Capitalismo e a astúcia da História. Trad. Anselmo da Costa. In: Revista Meditações, v. 14, p. 11-33, jul/dez, 2009.

FRASER, N. Um futuro para o marxismo. Trad. Dina Lida Kiroshita. Revista Novos Rumos, ano 14, no 29, 1999

FRASER, N. HONNETH, A. Redistribution or Recognition? A Political-Philosophical HORKHEIMER, M. Teoria tradicional e Teoria Crítica. In: Os pensadores vol.16. São Paulo: Nova cultural, 1991. 
REVISTA IDEAÇÃO, EDIÇÃO ESPECIAL 2018

MARCUSE, H. Eros e Civilização. Zahar editora, Rio de Janeiro, 1975.

MARCUSE, H. Marxism and Feminism. In: The new left in the 1960's - Collected papers of Hebert Marcuse Vol. 3. Org: Douglas Kellner. Routledger: New York, 2005.

SILVA, J B. Marxismo e Reconhecimento. In: Crítica Marxista, n³1, p. 139-153, 2010. 